\title{
APRENDIZADO INTERATIVO EM AMBIENTES COMPLEXOS E EVOLUTIVOS
}

José Henrique Bassi Souza Sperancini, Josmar Cappa e Marcia Carvalho de Azevedo

\section{Resumo}

O sistema mundial de produção-consumo do século XIX, no qual os países industrializados importavam insumos de países pobres e exportavam manufaturas, sofreu profundas alterações. O aumento da população ampliou o mercado permitindo maior concorrência, especialização e novas tecnologias. Na segunda metade do século XX a produção industrial havia se espalhado pelo planeta. No final do mesmo século, grande parte da produção já estava fragmentada em escala global. Novos sistemas produtivos nacionais passaram a competir, dividir tarefas e a interagir no mercado internacional. A divisão fabril descrita por Adam Smith se tornou mundial e novos tipos de vínculos financeiros e tecnológicos criaram uma racionalidade produtiva global e um “comércio de tarefas”. O resultado mais visível desse novo arranjo produtivo é a inigualável capacidade de criar riqueza e novidades dos países integrados no espaço global. Entretanto, as diferenças entre a produtividade, a criatividade e os níveis de renda e consumo entre os países podem aumentar devido às diferenças nos ritmos de aprendizagem das organizações e nas condições de inserção das empresas nas redes econômicas globais.

O objetivo desse trabalho é recorrer aos clássicos do pensamento econômico institucionalista e evolucionista para entender como o acesso pleno ao conhecimento e à aprendizagem intensiva podem ser determinantes em ambientes seletivos. O artigo conclui que os modernos sistemas produtivos dependem da capacidade de geração, compartilhamento, seleção e uso do conhecimento. A construção e a aplicação do conhecimento, hoje, exigem grande interação entre atores especializados e “feedback" entre ciência, engenharia, desenvolvimento, produção e marketing.

Palavras-chave: cadeia global de valor, aprendizado interativo e Brasil

\begin{abstract}
During the 19th century, the global system of production and consumption, based on the international trade between industrialized nation and the exporters of natural resources has seen an important transformation. This fact is consequence of the rise of new consumers as part of developing countries catch up, has brought the fragmentation of production system on a global scale known as global value chain. The global value chain has imposed a new international labor division in the manufacturing sector.
\end{abstract}

Again, as once stated by Adam Smith, the labor division has created new new types of financial and technological ties with the old problem of inequality within the economic system based on different 
levels of productivity as part of different levels of knowledge and innovation, which is as barrier for new entrants.

Taking in consideration these problems, the aim of this paper is to understand the importantce of knowledge intensive learning dynamics as part of this processe. In order to do so, the paper use a theoretucal framework based on classic, institutionalist, and evolutionary school of thoughts. We concluded that in contemporary production systems depend on generating capacity, sharing, selection and use of knowledge. The construction and application of knowledge, today, require great interaction between specialized actors within an interplay between science, engineering, production and marketing systems.

Key words: global value chain, interactive learning and Brazil.

JEL: O33 - Technological Change: Choices and Consequences. Diffusion Processes.

\section{Introdução}

O progresso econômico requer o aumento do volume de comércio, uma crescente subdivisão de funções e a interação entre um número cada vez maior de agentes. A cada dia fica mais evidente que é preciso um trabalho interativo de indivíduos, empresas e sistemas produtivos especializados para expandir a produtividade.

À medida que as formas primitivas de vida ficaram mais complexas, isto é, suas partes se diferenciaram, a dependência entre suas partes aumentou. No limite, a atividade e a existência de cada fração somente se tornou possível com as atividades das demais; a longevidade do todo tornou-se maior do que a vida de cada fragmento. No mundo econômico também ocorreu um processo de crescente especialização e interação em um contínuo aperfeiçoamento da estrutura produtiva. Mas por que ocorreu esse fenômeno? Para refletir sobre essa indagação o artigo recorre ao pensamento de clássicos do pensamento econômico. Optamos por escolher os autores que estabeleceram um paralelo entre a economia, a biologia e o processo de aprendizagem.

No primeiro item o artigo trata do conceito de diferenciação e seu papel no processo de aprendizagem. Para isso, recorre ao modelo institucional vinculado à Nova Economia Institucional e ao “Velho Institucionalismo”. O objetivo é preparar o leitor para refletir sobre o próximo item que trata da relação entre as instituições e o desenvolvimento das organizações. Como os autores interpretam o mundo econômico sob a ótica evolutiva o item seguinte explora brevemente o papel da seleção evolutiva de instituições. Na parte final do artigo são tratados os temas do processo de aprendizado em cadeias globais 
de valores. Por fim, o artigo não trata de pesquisas ou estudo de caso. O objetivo é explorar modelagens teóricas e conceitos úteis para entender o moderno ambiente de competição e aprendizagem empresarial.

\section{Diferenciação e Aprendizagem}

No século XIX, Malthus (1836), Spencer (1858, 1859, 1860, 1882 e 1891), Durkheim (1982) e Darwin (1909), entre outros, notaram que os estímulos externos impulsionam o desenvolvimento de sistemas complexos como os organismos vivos e a sociedade. As mutações, em resposta às dificuldades do ambiente, criaram as formas superiores de vida, a civilização e o progresso material. Sem desafios, provavelmente, a história humana teria sido marcada pela letargia, pela monotonia e pela rotina.

O recurso ao conceito de diferenciação com especialização descrito por Spencer (1882 e 1891) e Darwin (1909) na biologia, e por Smith (1904) e Marshall (1890) na economia é uma ferramenta teórica que busca dar conta de uma modelagem que privilegia o entendimento de um ambiente no qual o novo e a criação estão presentes. Nega, portanto, as modelagens que se apoiam em dualismos de forças opostas. Substitui a mecânica clássica pela “ciência da evolução” baseada nos sistemas complexos dinâmicos ou nas “estruturas dissipativa” e de “não-equilíbrio” (Prigogine, 2002, p. 15).

\section{Por exemplo, para Spencer}

Economistas há muito descrevem a evolução que, começando com uma tribo cujos membros solidariamente executam as mesmas ações cada um por si, termina com uma comunidade civilizada, cujos membros solidariamente executam ações diferentes (...) o produtor solitário de qualquer mercadoria é transformado em uma combinação de produtores que, muito tempo depois de consideráveis progressos feitos na divisão do trabalho entre as diferentes classes de trabalhadores (...) quando as estradas e outros meios de transporte tornam-se numerosos e bons, os diferentes distritos começam a assumir funções diferentes, e tornar-se mutuamente dependentes. (...). Atualmente essa subdivisão de funções mostra-se não apenas entre as diferentes partes de uma mesma nação, mas entre diferentes nações. Essa troca de mercadorias, que de livre comércio promete tão grandemente a aumentar, acabará por ter o efeito de se especializar, em maior ou menor grau, a indústria de cada povo. Assim o que começou com uma tribo bárbara, quase se não totalmente homogênea nas funções de seus membros, o progresso foi, e ainda está levando a um agregado econômico de toda a raça humana (Spencer, 1882, p. 238).

O resultado da especialização dos atores econômicos é mais eficiência, liberdade e criatividade no sistema produtivo. Seu efeito mais visível é a inigualável capacidade de criar riqueza e novidades. Isto porque, na economia de mercado, o fator fundamental não é a competição, mas “a competição do artigo novo, da nova tecnologia, da nova fonte de fornecimento, do novo tipo de organização (...) competição por um custo decisivo ou uma vantagem de qualidade” (Schumpeter, 1943: 107). Hodgson (2003a) argumenta que:

O capitalismo é o sistema econômico mais dinâmico da história humana. Sua lógica de condução envolve a expansão e a diversificação dos múltiplos mercados. Como ele se expande, as empresas procuram sempre novas oportunidades para o comércio e ganho. Como a concorrência se intensifica dentro de determinados mercados, as empresas com fins lucrativos inovam e diversificam os seus produtos na criação incessante de novos nichos de mercado (...). A busca competitiva pelo lucro pressiona as empresas a investirem em novas tecnologias ou novas habilidades. Nessa busca pela inovação, as fronteiras da ciência e da tecnologia são avançadas, levando a novas áreas do conhecimento e da 
investigação. Os serviços são geralmente mais diversificados do que bens manufaturados, portanto, a diversidade também aumenta com o aumento do tamanho relativo do setor de serviços. Novas e variadas formas organizacionais são concebidas para aumentar a produtividade e gerenciar um número exponencialmente crescente de produtos e processos. (Hodgson, 2003a, p. 471)

Entretanto, as diferenças entre a produtividade e os níveis de renda e consumo entre os países e regiões não estão diminuindo. Existe uma visível melhoria nos padrões de vida da humanidade, mas as distâncias entre produtividades nacionais podem aumentar devido às diferenças na infraestrutura de apoio à produção, nos ritmos de aprendizagem das organizações e nas capacidades de inserção das empresas nas redes econômicas globais. Mas, como explicar o mecanismo pelo qual algumas sociedades conseguem aprender e produzir conhecimento com velocidade e eficiência? Este é um dos principais itens relativos ao poder competitivo das empresas, cidades, regiões e países. Para entender esse mecanismo, em sua forma básica de operação, é preciso entender o conceito de “instituição”.

\section{Modelos Mentais e Instituições Favoráveis ao Aprendizado}

Para North (1994a, p. 363), as estruturas de crenças "é uma parte essencial das sociedades modernas”. Os valores, crenças, hábitos, costumes e interpretações sobre os fenômenos naturais e sociais; os entendimentos a respeito de "como o mundo funciona”, são criações humanas desenvolvidas para enfrentar desafios e situações adversas do meio em que vivemos. Esses “modelos mentais” são criados pelo sistema cognitivo para interpretar o ambiente e melhorar as condições de vida.

Segundo Rizzello (2003, pp. 15 e 10) a mente humana tem o papel central nos processos econômicos. Por isso é de especial importância o modelo de North. Nele, os “modelos mentais” são as representações internas que a mente constrói ao interpretar o ambiente externo enquanto que as “instituições” são os mecanismos externos criados para estruturar tais modelos. (Ambrosino, 2012 e Ambrosino, Fontana e Gigante, 2015, p. 15). Muitos se transformam em modos comuns de comportamento e em estruturas sociais e econômicas denominadas de “instituições”, isto é, regras formais e normas informais de comportamento. Tais "sistemas duradouros de regras socialmente enraizadas" (Hodgson, 2009b, p. 16) interferem decisivamente na forma como os indivíduos e as organizações enfrentam os desafios cotidianos e criam inovações e soluções para problemas enfrentados.

Nas palavras do "velho institucionalista” Thorstein Veblen, as instituições são "os hábitos comuns de pensamento com relação a determinadas relações e funções específicas do indivíduo e da comunidade” (Veblen, 1918, p. 92) e “(...) um resultado natural do hábito” (Veblen, 1909b, p. 628). Algumas instituições são formais, estabelecidas por leis ou regras de conduta, enquanto outras são mais espontâneas e os indivíduos nem notam mais porque agem daquela forma. As “instituições” formam a herança cultural de uma sociedade, moldam e organizam esta sociedade e interferem profundamente na vida das empresas e dos agentes econômicos. 
As instituições são limitações humanamente concebidas que estruturam a interação humana. Elas são feitas de restrições formais (por exemplo, regras, leis, constituições), restrições informais (por exemplo, normas de comportamento, convenções, códigos auto-impostos de conduta), e suas características de execução. Juntas, elas definem a estrutura de incentivos das sociedades e das economias especificamente. (North, 1994a, p. 360)

Hayek, igualmente utilizou o termo instituição de forma semelhante quando afirmou que:

Nós fazemos uso constante de fórmulas, símbolos e regras cujo significado não compreendemos e através do uso deles nos valemos da assistência de conhecimento que, individualmente, não possuímos. Desenvolvemos essas práticas e instituições através da construção de hábitos e instituições que se revelaram bem-sucedidas em sua própria esfera e que tenham, por sua vez tornar-se o fundamento da civilização que construímos (Hayek, 1945, p. 528)

As instituições são as células que constroem as distintas sociedades. Portanto, o ambiente no qual ocorre o aprendizado empresarial é o ambiente da criação de instituições, seja ele local ou global. Mas, qual a importância das relações entre as instituições e as organizações nos processos de aprendizado das empresas? Para refletir sobre essa indagação é preciso distinguir “instituição” de “organização”. Estas:

... são constituídas de grupos de indivíduos unidos por um objetivo comum para atingir certas metas. Organizações incluem órgãos políticos (por exemplo, os partidos políticos, o Senado, a Câmara de Vereadores, órgãos reguladores), organismos económicos (por exemplo, empresas, sindicatos, agricultura familiar, cooperativas) corpos sociais (por exemplo, igrejas, clubes, associações atléticas), e estabelecimentos de ensino (por exemplo, escolas, universidades, centros de formação profissional). (North, 1994a, p. 361)

É verdade que a maioria das relações econômicas ocorre entre indivíduos que, em sua maioria, jamais se conhecerão (Friedman, 1962), mas a produção tem lugar apenas na sociedade e somente através da cooperação entre indivíduos. É esta comunidade que transmite as tradições, as ferramentas e o conhecimento técnico sem os quais não existe organização industrial e nem relação econômica entre indivíduos. O indivíduo isolado não é um agente produtivo (Veblen, 1898b). Desse modo, como afirmou North (1993b, 1994a, p. 361 e 1994b, p. 04), é a interação entre instituições e organizações que molda a evolução institucional de uma economia. Para entender o processo competitivo de um sistema produtivo as “cinco proposições sobre a mudança institucional” de North são bastante úteis. Para North,

1. A interação contínua entre instituições e organizações no cenário econômico de escassez e, portanto, a concorrência é a fonte de mudança institucional.

2. A concorrência obriga a empresa a investir continuamente em habilidades e conhecimentos para sobreviver. Os tipos de habilidades e conhecimentos que os indivíduos e suas organizações adquirem irão moldar as percepções sobre oportunidades em evolução e, portanto, as escolhas que alteram gradativamente as instituições.

3. O quadro institucional fornece os incentivos que ditam os tipos de habilidades e conhecimentos percebidos para ter a recompensa máxima.

4. As percepções são derivadas das construções mentais dos jogadores. 
5. As economias de escopo, complementaridades e externalidades de rede de uma matriz institucional faz a mudança institucional esmagadoramente incrementais e dependente da trajetória. (North, 1994b, p. 13, 1993b; 1994a e 1996b, p. 07)

A chave, portanto, para entender como ocorre a mudança institucional, são os tipos de aprendizagem e de habilidades que os empresários e as suas organizações adquirem. Entretanto, do ponto de vista global, para North (1994a e b), não há um seguro progresso evolutivo ou qualquer garantia da melhoria no desempenho econômico apenas por conta das mudanças institucionais (1994a, p. 363; 1994b, p. 14; 1996b, p. 07). A matriz institucional apenas define o conjunto e o prêmio (retorno) das oportunidades econômicas com base no qual as organizações são criadas.

\section{O Processo Evolutivo Não Consumativo}

As instituições estabelecidas se chocam com a realidade objetiva em mudança. A evolução dessa interação modifica o formato que a cada sociedade particular toma e a forma como as organizações solucionam seus problemas. Para Veblen, as "instituições devem mudar com a mudança das circunstâncias (...). O desenvolvimento dessas instituições é o desenvolvimento da sociedade” (Veblen, 1918, pág. 92).

O crescimento da cultura é uma sequência cumulativa de habituação, e seus modos e meios são a resposta habitual da natureza humana às exigências que variam incontinenti, cumulativamente, mas com algo de uma sequência consistente nas variações cumulativas que assim avançam, - incontinenti, porque cada novo movimento cria uma nova situação que induz um nova variação da maneira habitual de resposta; cumulativamente, porque cada nova situação é uma variação do que aconteceu antes dela e incorpora como fatores causais todos os que têm sido realizados pelo que se passou antes ... (Veblen, 1909b, p. 628)

A sucessão de gerações e as mudanças na realidade social fazem com que os valores recebidos sejam questionados e novos valores, crenças e hábitos sejam criados. Nesse processo evolutivo a sociedade, os profissionais e as empresas repensam, criam e selecionam constantemente seus valores, crenças e hábitos; aprendem e formam sistemas de produção de bens e conhecimentos com diferentes graus de eficiência.

\footnotetext{
A vida humana (...) é uma luta pela existência, e, portanto, um processo de adaptação seletiva. A evolução da estrutura social foi um processo de seleção natural das instituições. O progresso que se fez e que se vai fazendo nas instituições humanas e no caráter humano pode ser considerado, de um modo geral, uma seleção natural dos hábitos mentais mais aptos e um processo de adaptação forçada dos indivíduos a um ambiente que vem mudando progressivamente mediante o desenvolvimento da comunidade e a mudança das instituições sob as quais o homem vive (Veblen, 1918, p. 92).
}

Desse modo, as instituições operam como os genes. Transmitem uma "hereditariedade cultural”; favorecem uma permanência de valores, mas também abrem a possibilidade do surgimento de novos valores e hábitos. Formam uma ponte que liga o passado e o futuro de uma estrutura complexa - a sociedade - em um ambiente de seleção. E por ser um ambiente de seleção o resultado é sempre imprevisível, é não consumativo. Para Hodgson (1997, p. 50)

Enquanto na esfera biótica as fontes primordiais da variedade são a mutação genética e a recombinação, no sistema socioeconômico a variedade é muitas vezes fruto da criatividade humana. Na evolução 
filogenética do tipo 2.2.2 (não consumativa), esta criatividade e esta variedade continuada são suficientes para garantir a inexistência de um equilíbrio permanente. A mudança qualitativa tem maior alcance e é mais ampla. Mesmo que exista equilíbrio, este equilíbrio pode tornar-se ‘descontínuo’ ou ser destruído (Hodgson, 1997, p. 50).

No mesmo sentido Hayek alerta que,

... toda a evolução, cultural, bem como biológica, é um processo de contínua adaptação a acontecimentos imprevisíveis, a circunstâncias contingentes que não poderiam ter sido previstas. Esta é outra razão pela qual a teoria da evolução nunca pode nos colocar na posição de forma racional prever e controlar a evolução futura. Tudo o que podemos fazer é mostrar como estruturas complexas carregam dentro de si um meio de correção que leva a novos desenvolvimentos evolutivos que são, no entanto, de acordo com sua própria natureza, inevitavelmente imprevisíveis (Hayek, 1992, p. 25).

Hayek também enfatiza o caráter espontâneo na evolução do sistema produtivo.

“(...) nossa civilização depende, não apenas quanto à sua origem, mas também quanto à sua preservação, do que somente podemos definir com precisão como a ordem espontânea da cooperação humana, ordem conhecida mais comumente, embora de modo algo equivocado, como capitalismo. Para compreender nossa civilização é preciso notar que esta ordem não foi fruto do desígnio ou da intenção humana, mas nasceu espontaneamente; nasceu de certos costumes tradicionais e em grande parte morais, muitos dos quais desagradam aos homens, cuja importância eles em geral não entendem, e cuja validade não podem provar, e que, não obstante, se difundiram de modo relativamente rápido, graças a uma seleção evolucionária - o crescimento comparativo da população e da riqueza, dos grupos que por acaso os seguiram” (Hayek, 1992, p. 06)

Veblen entendia o desenvolvimento como um processo evolutivo baseado em princípios darwinistas (Hodgson, 2003b e 2008, p. 402 e 2012, p. 03). Mais recentemente Hodgson acrescentou que é impossível prever a natureza e a forma da mudança social partindo do ponto de vista evolutivo darwinista. Isto porque Com base no darwinismo, a mudança ocorreria em consequência de variações aleatórias que são uma fonte de imprevisibilidade e privam a evolução de um objetivo predeterminado.” (Hodgson, 1997, p. 45).

Para Hodgson as instituições responsáveis pelo desenvolvimento econômico são selecionadas em um processo que inclui os três princípios darwinistas centrais (Coccia, 2005; Hodgson, 2003b, 2004b, 2008 e 2012). O primeiro é a necessidade de existir variação entre os membros de uma espécie. O segundo diz que deve haver um mecanismo de continuidade, isto é, a hereditariedade. Por fim, o terceiro princípio - a seleção natural - estipulando que os organismos mais adaptados conseguem aumentar o número de descendentes, ou as variações que transmitem garantem vantagens dos descendentes na luta pela sobrevivência. Na verdade, Darwin já havia sugerido que o processo de seleção poderia ser aplicado para entender aspectos importantes da sociedade formada pelos “seres morais” (Aldrich et al. 2008), isto é, aqueles seres que são capazes de “comparar o seu passado e as ações futuras ou motivos, e de aprovação ou desaprovação deles” (Darwin, 1871, p. 88).

Assim, a cultura seria um “esquema evolutivo” (Veblen, 1898a, p. 377 e 1898c, p. 191), isto é, um processo dinâmico de mutação no qual cada mudança cria uma nova situação que induz a uma nova variação. Cada nova variação é a variação anterior acrescida de fatores fortuitos. Dessa forma, a 
sociedade tende a sofrer mutações continuadas rumo ao desconhecido. Entretanto, algumas instituições são claramente favoráveis à construção de sistemas econômicos eficientes e criativos. Ao menos é o que alguns clássicos do pensamento econômico sempre enfatizaram. Por exemplo, a liberdade, o respeito à propriedade privada e o livre mercado são instituições fundamentais. Mas, também outros valores “morais” herdados, criados e selecionados favorecem a criação de ambientes propícios ao desenvolvimento das potencialidades criativas e inovadoras dos indivíduos.

Veblen destacou a busca humana pelo reconhecimento social por meio da participação produtiva do indivíduo enfatizando o conceito de “emulation” (Veblen, 1898c). A palavra emulação representa o sentimento que estimula o indivíduo ao zelo e à busca por se igualar ou exceder os outros naquilo que é bom e apreciável. O indivíduo busca por satisfação pessoal, reconhecimento e aprovação pela comunidade por meio da obtenção da eficácia, da eficiência e das melhores condutas (Veblen, 1898c). Agindo desse modo os seres humanos colocaram em marcha um processo espontâneo de construção de um ambiente pacífico e propício ao desenvolvimento e de sistemas produtivos cada vez mais eficientes. Porém, o trabalho cooperado seria a única possibilidade de sobrevivência de um ser desprovido de defesas naturais. Somente vivendo em sociedade teria sido possível criar um ambiente favorável à sobrevivência (Veblen, 1898c, p. 193). Moldando o ambiente por meio da organização social os seres humanos puderam sobreviver e melhorar seu padrão de vida.

\section{As Cadeias Produtivas Globais e o Aprendizado Global}

Por séculos os economistas têm enfatizado os benefícios da expansão do comércio. Ricardo, por exemplo, enfatizava que o comércio exterior era "altamente benéfico para um país, na medida em que eleva o montante e a diversidade dos objetos nos quais o rendimento pode ser gasto, e na medida em que, pela abundância e barateamento das mercadorias, incentiva a poupança e a acumulação de capital...” (Ricardo, 1821, p. 89). Nesse sistema comercial perfeitamente livre, cada país dedicaria seu capital e seu trabalho à atividade que lhe seja mais benéfica.

\footnotetext{
"Essa busca de vantagem individual está admiravelmente associada ao bem universal do conjunto dos países. Estimulando a dedicação ao trabalho, recompensando a engenhosidade e propiciando o uso mais eficaz das potencialidades proporcionadas pela natureza, distribui-se o trabalho de modo mais eficiente e mais econômico, enquanto, pelo aumento geral do volume de produtos, difunde-se o benefício de modo geral e une-se a sociedade universal de todas as nações do mundo civilizado por laços comuns de interesse e de intercâmbio (Ricardo, 1996, p. 97 ou 1821, p. 90)
}

Além da riqueza representada pela diversidade e disponibilidade de bens para serem consumidos, a participação ativa de um país no comércio internacional amplia a capacidade de aprendizagem e inovação das empresas.

Vimos que para os clássicos do pensamento econômico e social, ambientes diferentes tendem a produzir condições de vidas distintas e indivíduos com características diferentes. Assim, "Se as 
instituições são as regras do jogo, as organizações e seus empresários são os jogadores” (North, 1994a, p. 361). Portanto, a direção dos investimentos empresariais em habilidades e conhecimentos refletem, também, a estrutura de incentivos da matriz institucional. Desse modo, podemos imaginar que a interação global cria instituições favoráveis ao desenvolvimento tecnológico das empresas. Certamente o isolamento dificulta às empresas a aquisição de conhecimentos, habilidades e capacidades necessárias para gerenciar contratos globais multi-agentes. No espaço global, se manifesta uma maior diversidade de exigências sobre os atores econômicos. Também é no espaço ampliado que os agentes percebem que podem melhorar seus produtos, processos e tecnologias de gestão. Tal fenômeno ocorre de forma ampliada no espaço global porque, como afirmou Andy Clark, o ambiente externo interfere decisivamente no processo de aprendizagem.

\begin{abstract}
Estas estruturas externas e circunstâncias atuam como filtros e restrições sobre os espaços de possíveis respostas em tempo real. O mais importante, entre essas estruturas e circunstâncias, no caso da razão humana, são os artefatos culturais da linguagem e das instituições sociais e econômicas. Modelos de tomada de decisão racional precisam situar o raciocínio do agente apenas como um elemento de um sistema de feedback complexo e sensível ao tempo em que essas estruturas externas desempenham um papel importante. Assim, é fundamental que entendamos a interação complexa e mutuamente moduladora entre cognição individual e os laços ambientais prolongados em que participa. (Clark, 1997, p. 269)
\end{abstract}

\title{
Aprendizado Global
}

Segundo Foster, a complexidade em sistemas produtivos “... constitui uma força poderosa no desenvolvimento de sistemas econômicos muito sofisticados” (Foster, 2004a, p. 07). Assim, é possível inferir que as empresas, os consumidores e os sistemas produtivos pouco expostos a estímulos globais tenham mais dificuldades de se tornarem inovadores, criativos e dinâmicos.

No atual sistema mundial de produção grande parte da atividade econômica está fragmentada em escala global. A divisão fabril do trabalho descrita por Adam Smith envolveu o mundo moderno transformado a “aldeia global” em uma “fábrica global”. O aumento da população ampliou o mercado permitindo uma maior especialização e diversidade de tecnologias, profissões, produtos, processos e formas de interação.

Sabe-se que sistemas produtivos interligados em escala internacional existem desde o império romano, entretanto, atualmente, novos tipos de vínculos financeiros e tecnológicos criaram uma nova racionalidade produtiva. Segundo a OCDE (2011) a globalização chegou a um ritmo e uma dimensão inéditos.

“(...) tem aumentado o comércio internacional, aprofundado a integração econômica (...), e elevado a fragmentação geográfica dos processos de produção que amplificam a complexidade das cadeias de valor mundiais. (...) Cada vez mais a inovação tem sido vista como um fator crítico para dar respostas a estes desafios" 
Franco (1999, p. 30) argumenta ocorreu uma proliferação de novas formas de investimento internacional na forma de vínculos financeiros e tecnológicos, “estabelecendo uma racionalidade global no processo produtivo sem necessariamente envolver a complexidade do processo de investimento direto”. E, segundo o “World Trade Organization” (Wto/Jetro, 2011), em 2009, excluindo petróleo, metade das mercadorias transacionadas internacionalmente eram bens intermediários. Assim, para a WTO surgiu um “comércio de tarefas” no lugar de um comércio de bens. Tal transformação, segundo a mesma organização, tende a reforçar a especialização das economias nacionais.

Como previsto por Spencer (1891) e Marshall (1890), no novo arranjo da indústria, a “especialização vertical” ou a “cadeia de global de valores” aumentou a interdependência entre parques industriais nacionais. Assim, o novo sistema produtivo mais uma vez modificou as funções do Estado, do comércio exterior, dos sistemas de inovação e das estruturas produtivas e de apoio para o desenvolvimento econômico (METI, 2004; Stal 2010; Wto/Ide-Jetro, 2011).

Ocorre que o avanço na fragmentação da produção não eliminou o diferencial de produtividade entre os países. Segundo Franco (1999, p. 38) "prevalecem enormes diferenciais internacionais e interregionais nos níveis absolutos de produtividade”. Isto ocorre porque a velocidade das mudanças tecnológicas é global, mas os ritmos de aprendizagem dos agentes e a capacidade de inserção nas redes econômicas globais são distintos, o que muda o poder competitivo entre eles.

North (1994a) destaca que a velocidade da mudança econômica é uma função da taxa de aprendizagem. A direção dessa mudança depende da aquisição de diferentes tipos de conhecimento em função dos ganhos esperados. Na sociedade em rede atual, a capacidade de acesso pleno ao conhecimento e de construção de relações de aprendizagem intensiva determinam a posição socioeconômica dos indivíduos e das empresas (David e Foray, 1995).

A esse respeito é preciso considerar que no capitalismo as possibilidades de aumento da complexidade socioeconômica e da especialização das habilidades são grandes. Hodgson sustenta que as melhorias na comunicação e na mobilidade podem ajudar a aumentar a complexidade impulsionando a diversificação de produtos. A crescente variedade das tarefas exige maior flexibilidade e capacidade de aprendizagem das populações empregadas no sistema produtivo. Por isso, “estamos diante de um sistema capitalista mais complexo e de um cenário de "competências reforçadas e crescente intensidade do conhecimento” (Hodgson, 2003a, p. 275).

As mudanças e invenções técnicas, a descoberta de novas fontes de abastecimento, o desenvolvimento de novas rotas comerciais e alterações na demanda podem impedir que determinadas empresas compartilhem a melhoria geral (Mitchell, 1941). Entretanto, hoje, o sucesso dos profissionais, 
das empresas, dos segmentos produtivos e das economias nacionais depende da capacidade de gerar, selecionar e utilizar o conhecimento. Ocorre que tal capacitação é desenvolvida de forma interativa e compartilhada entre vários atores (Jacobs, 2001). O processo de inovação requer uma grande interação entre diferentes atores - empresas, laboratórios, instituições de pesquisa e ensino e consumidores - e “feedback” entre ciência, engenharia, desenvolvimento, produção e marketing. Tal divisão de tarefas permite que as empresas impulsionem um aprendizado interativo; reduzam os custos e os riscos da inovação; acessem resultados de pesquisas, tecnologias e componentes e compartilhem atividades de produção, distribuição e marketing (OECD, 1996).

Em anos recentes, no entanto, as estratégias de outsourcing sofreram uma profunda evolução, a partir de formas simples de contratos de produção assumidos com terceiros para acordos que envolvem funções e atividades que, requerem "Competências centrais", ou que fazem parte do "core business", até então consideradas inseparáveis da empresa (...). A tendência hoje é de atingir 'Global sourcing' e 'offshoring', ou seja, a terceirização que envolve terceirizações localizadas em países que não a do ‘outsourcee’. Esta tendência de externalizar a maioria das funções e processos pode levar a um extremo (...) o 'extremo outsourcing’, e levar à formação de uma organização virtual, uma empresa que se caracteriza pela coordenação do puro negócio de seus negócios, onde todos os processos económicos e produtivos foram terceirizados através da formação de uma rede estável mas flexível. (Mella ; Pellicelli, 2012, p. 116)

Assim, a cadeia global de valores pode ser considerada uma inovação schumpteriana do tipo “nova organização” (Schumpeter 1934 e OECD, 2005) que demonstra uma elevação nos níveis de produtividade. E, também, mostra que o aumento da produtividade vem derivando fundamentalmente do fenômeno da divisão do trabalho, isto é, da diferenciação e interação entre indivíduos.

Como a antiga linha de produção descrita por Smith se fragmentou em escala global é fundamental que as empresas participem das correntes dinâmicas do comércio internacional. Estabelecer relações econômicas, tecnológicas e científicas com sistemas produtivos inovadores e que contam com mercados sofisticados é indispensável (Porter, 1989 e 1990). Ficar isolado ou sem relações com os países ricos é condenar a empresa a uma regressão tecnológica que, provavelmente, irá comprometer a capacidade futura de inserção competitiva no mercado global. A participação das empresas nas grandes redes globais é fundamental para a aprendizagem e evolução das empresas e do sistema de apoio (indústrias correlatas e sistemas de inovação). Isto ocorre porque vem aumentando as exigências quanto a coordenação de tarefas em escala global e a participação em cadeias de negócios que estimulam as inovações tecnológicas, o aprendizado e as competências gerenciais.

Fixar marcas em grandes mercados e poder contar com consumidores exigentes e sofisticados, diversificar riscos, ganhar escala e economia de escopo também são benefícios que podem surgir da internacionalização (Dunning, 2001; Stal, 2010). Obviamente que a capacidade de uma empresa se beneficiar de tais atividades depende dos ativos e competências que possui antes do processo de 
internacionalização (Dunning, 2001). Também argumentam Oliveira e Sbragia (2012a e 2012b) que a criação de estruturas integradas de tomada de decisão em uma cadeia de produção que incorpora uma grande quantidade de agentes requer habilidades avançadas das organizações.

Participando da cadeia global de valores é possível elevar a intensidade do aprendizado por meio de contatos entre culturas, padrões de consumo, tendências de mercados; cooperação entre empresas e coordenações globais de tarefas. Jacobs que define o desenvolvimento como diferenciações emergindo de generalidades acrescenta que tal "processo é aberto e produz diversidade crescente além de numerosas, múltiplas, intricadas relações crescentes de co-desenvolvimento” (Jacobs, 2001, p. 30). Assim, o desenvolvimento depende de co-desenvolvimento. "Ele opera com uma rede de co-desenvolvimentos interdependentes. Sem essa rede não há desenvolvimento” (Jacobs, 2001, p. 40).

Para North as mudanças institucionais realizadas para aproveitar o novo ambiente produtivo são mais importantes do que a mudança da organização econômica. A criação de mercados eficientes a partir da segunda revolução industrial, por exemplo, exigiu a mudança de toda a estrutura social, incluindo os sistemas políticos e econômicos e de educação e treinamento. Desse modo, a chave para compreender a natureza dos mercados eficientes é o tipo de aprendizagem que as organizações adquirem. A forma como as organizações evoluem - interagindo com as instituições e aproveitando os benefícios das modernas tecnologias - é fundamental para obter baixos níveis de custos de transação e de produção (1993a, 1993b, 1994d e 1996c). "São as instituições econômicas e políticas de uma sociedade (em conjunto com a tecnologia empregada) que determinam a eficiência dos mercados” (North, 1993a, p. 04, 1996c, p. 08).

\section{Conclusão}

O objetivo desse trabalho foi usar ferramentas teóricas dos clássicos do pensamento econômico institucionalista e evolucionista para entender o papel da aprendizagem interativa em ambientes seletivos e evolutivos. Refletindo sobre suas modelagens é possível concluir que os modernos sistemas produtivos dependem da capacidade de geração, compartilhamento, seleção e uso do conhecimento.

A construção e a aplicação do conhecimento, hoje, exigem grande interação entre atores especializados. O sistema produtivo fragmentado mundialmente gera um resultado superior do ponto de vista da aprendizagem empresarial já que oferece maior complexidade e mais estímulos para empresas, profissionais e instituições. No espaço global as empresas e profissionais são expostos a uma elevada diversidade de clientes, tecnologias e fornecedores. As relações em um sistema estruturado, interconectado e interativo aumentam a capacitação tecnológica e gerencial, necessárias para melhorar produtos, processos e tecnologias de gestão. 
A economia global é, portanto, um sistema complexo e evolutivo que exige uma melhor capacidade de resposta das empresas, dos profissionais e dos órgãos públicos. Isto ocorre porque os métodos de gestão e as estratégias são dependentes do ambiente no qual as empresas operam e o avanço tecnológico ocorre por meio da interação entre um grande número de atores especializados. Dessa forma, as empresas que participam de grandes mercados e redes de inovação, distribuição e produção se encontram em vantagem para aprender e galgar estágios superiores na escala tecnológica e de valores.

A interação entre os agentes especializados e capazes de absorver um grande volume de informações sobre tecnologias e tendências de mercado forma redes de co-desenvolvimento essenciais para as empresas. Participando dessas redes é possível melhorar a tomada de decisão, uma vez que amplia a capacidade de recolher, selecionar, priorizar e interpretar informações em escala mundial impulsionando o sistema produtivo em direção aos bens e serviços com maior sofisticação, valor agregado e conhecimento incorporado.

O acesso pleno ao conhecimento e a capacidade de construir relações de aprendizagem intensiva podem ser determinantes na posição socioeconômica atual dos agentes econômicos. A sobrevivência e o sucesso dos profissionais, das empresas e dos segmentos produtivos dependem da capacidade de geração, compartilhamento, seleção e uso do conhecimento. Ocorre que a construção e a aplicação do conhecimento, hoje, exigem uma grande interação entre diferentes atores especializados - empresas, laboratórios, instituições de pesquisa e ensino e consumidores - e “feedback” entre ciência, engenharia, desenvolvimento, produção e marketing.

A divisão de tarefas em escala global permite que as empresas impulsionem um aprendizado interativo; reduzam os custos e os riscos da inovação; acessem resultados de pesquisas, obtenham melhores tecnologias e componentes e compartilhem atividades de produção, distribuição e marketing. Assim, a eficiência da empresa individual depende do aprendizado no espaço global.

\section{BIBLIOGRAFIA}

ALDRICH, Howard E ; HODGSON Geoffrey M. ; HULL, David L. , KNUDSEN, Thorbjørn ; MOKYR, Joel and VANBERG, Viktor J. In Defence of Generalized Darwinismee, Journal of Evolutionary Economics, 18(5), October, 2008, pp. 577-96.

AMBROSINO, Angela ; FONTANA, Magda ; GIGANTE, Anna Azzurra. Shifting Boundaries In Economics: The Institutional Cognitive Strand. Dipartimento di Economia e Statistica "Cognetti de Martiis”. Working paper No. 44/2015, Università di Torino, 2015.

AMBROSINO, Angela. Cognizione ed Evoluzione Istituzionale: un rilevante punto di contatto fra Hayek e la teoria del cambiamento istituzionale di Veblen. Studi e Note di Economia, Anno XVII, n. 2-2012, pagg. 219-247. 
CLARK, Andy. Economic Reason: The Interplay of Individual Learning and External Structure. In Drobak, J.N. and J.V.C. Nye (eds.), The Frontiers of the New Institutional Economics, San Diego and London: Academic Press, 1997, 269-90.

COCCIA, Mario. Gli approcci biologici nell’economia dell’innovazione. [Biological Approaches within the Economics of Innovation]. WORKING PAPER CERIS-CNR, Anno 7, Nº $1-2005$.

DARWIN, Charles Robert. The Origin of Species. Edited By Charles W Eliot LL D. The Harvard Classics. New York: PF Collier \& Son, 1909.

DARWIN, Charles R. The Descent of Man, and Selection in Relation to Sex, 1stedn., 2 vols, ondon: Murray and New York: Hill, 1871.

DAVID, P. ; D. FORAY. Accessing and Expanding the Science and Technology Knowledge Base. STI Review, No. 16, OECD, 1995.

DUNNING, J. H. The Eclectic (OLI) Paradigm of international production: past, present and future. International journal of the economics of business, v. 8, n. 2, p. 173-190, 2001.

DURKHEIM, Émile. The Rules of Sociological Method. New York: The Free Press, 1982.

FOSTER, John. "From Simplistic to Complex Systems in Economics," Discussion Papers Series 335, School of Economics, University of Queensland, Australia, 2004.

FRANCO, Gustavo H. B. O Desafio Brasileiro: ensaios sobre desenvolvimento, globalização e moeda. São Paulo: Editora 34, 1999.

FRIEDMAN, Milton. Capitalism and Freedom. Chicago: University of Chicago Press, 1962.

HAYEK, Friedrich A. The use of knowledge in society. American Economic Review, vol. XXXV, n. 4, pp. 519-530. 1945.

HAYEK, Friedrich August von. The Fatal Conceit: The Errors of Socialism. Edited by W. W. BARTLEY, Great Britain, 1992.

HODGSON, Geoffrey. M.. Darwinism and Institutional Economics. Journal of Economic. Vol. 37, No. 1, A Symposium on David Hamilton's "Evolutionary Economics: A Study of Change in Economic Thought" (Mar., 2003b), pp. 85-97.

HODGSON, Geoffrey. M.. Economia e Evolução: o regresso da vida à teoria econômica. Oeiras: Celta, 1997.

HODGSON, Geoffrey. M.. Toward an Evolutionary and Moral Science: Remarks upon Receipt of the Veblen-Commons Award. Journal of Economic Issues. Vol. 46, No. 2, PAPERS FROM THE 2012 ANNUAL AFEE MEETING (JUNE 2012), pp. 265-275.

HODGSON, Geoffrey. M.. How Veblen Generalized Darwinism. Journal of Economic Issues. Vol. 42, No. 2, Papers from the 2008 AFEE Meeting (Jun., 2008), pp. 399-405. 
HODGSON, Geoffrey. M.. Institutional Economics into the Twenty-First Century', Studi e Note di Economia, 24(1), 2009b, pp. 3-26.

HODGSON, Geoffrey. M.. Capitalism, Complexity, and Inequality. Journal of Economic. Vol. 37, No. 2 (Jun., 2003a), pp. 471-478.

JACOBS, Jane. A Natureza das Economias. São Paulo: Beca Produções Culturais, 2001.

MALTHUS, Thomas Robert. Principles of Political Economy. London: W. Pickering, 1836.

MARSHALL, Alfred. Principles of Economics. London: Macmillan and Co. 1890, ed. 1920.

MELLA, Piero ; PELLICELLI, Michela The Strategies of Outsourcing and Offshoring. American International Journal of Contemporary Research. Vol. 2 No. 9; September 2012.

MINISTRY OF ECONOMY, TRADE \& INDUSTRY (METI). Nakagawa Report: Toward a Sustainable and Competitive Industrial Structure. Tokyo: May, 2004.

MITCHELL, Wesley Clair. Business Cycles and Their Causes. California: University of California Press, 1941.

NORTH, Douglass C. Economic Performance Through Time. The American Economic Review, Vol. 84, No. 3. (Jun., 1994a), pp. 359-368.

NORTH, Douglass C., Institutions and Credible Commitment. Economic History. EconWPA 9412002, 1994b.

NORTH, Douglass C. Five Propositions about Institutional Change. Economic History 9309001, EconWPA, 1993b.

NORTH, Douglass C.. Where Have We Been And Where Are We Going? Economic History 9612001, EconWPA, 1996b.

ORGANISATION FOR ECONOMIC CO-OPERATION AND DEVELOPMENT. The KnowledgeBased Economy. Paris: OECD, 1996.

ORGANISATION FOR ECONOMIC CO-OPERATION AND DEVELOPMENT. Oslo Manual: principes directeurs pour le recueil et l'interprétation des données sur l'innovation. Troisième édition. Paris: OECD, 2005.

PORTER, Michael. A Vantagem Competitiva das Nações. Rio de Janeiro: Editora Campus, 1989.

PORTER, Michael. Vantagem Competitiva: criando e sustentando um desempenho superior. Rio de Janeiro: Campus, 1990.

PRIGOGINE, Ilya. As Leis do Caos. São Paulo: Editora Unesp, 2002.

RICARDO, David. On the Principles of Political Economy and Taxation. Ontario: Batoche Books, 2001 Third edition, 1821. 
RIZZELLO, Salvatore. Towards A Cognitive Evolutionary Economics. Dipartimento di Economia e Statistica "Cognetti de Martiis". Centro di Studi sulla Storia e i Metodi dell’Economia Politica "Claudio Napoleoni", (CESMEP), Working paper No. 03/2003, Università di Torino.

OLIVEIRA, S. R. ; SBRAGIA, R. Innovation Value Chain Performance Based in Knowledge. American International Journal of Contemporary Research, v. 2, p. 1-9, 2012a.

OLIVEIRA, S. R. ; SBRAGIA, R. Modelling for Planning High Complexity Environment Based in Knowledge. American International Journal of Contemporary Research, v. 2, p. 118-133, 2012 b.

SCHUMPETER, Joseph Alois. The theory of economic development. Cambridge, MA: Harvard University Press, 1934.

SCHUMPETER, J. A. Capitalism, Socialism and Democracy. Taylor \& Francis e-Library, 2003. First published in the UK in 1943.

SMITH, Adam. An Inquiry Into the Nature and Causes of The Wealth of Nations. London: Edwin Canna, M. A. LLD, 1904.

SPENCER, Herbert. Essays: Scientific, Political and Speculative, Essays: Scientific, Political, and Speculative. Library Edition, London: Williams and Norgate, 1891.

SPENCER, Herbert. Progress: its law and cause with other disquisitions. New York: J. Fitzgerald \& co., 1882.

SPENCER, Herbert. (1858); Recent Astronomy and the Nebular Hypothesis. The Westminster Review, New Series Vol. 15, july-octuber, 1858. London: John Chapman, pp. 185-225.

SPENCER, Herbert. (1860); The Social Organism. The Westminster Review, New Series Vol. 17, january-april, 1860. London: George Manwaring, pp. 90-121.

SPENCER, Herbert. (1859); The Social Organism. The Westminster Review, Vol. 72, july-octuber, 1859. American Edition, New York: Leonard Scott \& Co., pp. 51-68.

STAL, E. Internacionalização de Empresas Brasileiras e o Papel da Inovação na Construção de Vantagens Competitivas. RAI-Revista de Administração e Inovação, v. 7, p. 118-147, 2010.

VEBLEN, Thorstein. The Limitations of Marginal Utility. Journal of Political Economy. Published by: The University of Chicago Press. Vol. 17, No. 9 (Nov., 1909b), pp. 620-636.

VEBLEN, Thorstein. The Beginning of Ownership. American Journal of Sociology, vol. 4, 1898b.

VEBLEN, Thorstein. The Instinct of Workmanship and the Irksomeness of LaborFree contentQuick View. American Journal of Sociology, Vol. 4, No. 2 (Sep., 1898c), pp. 187-201.

VEBLEN, Thorstein. Why is Economics not an Evolutionary Science? The Quarterly Journal of Economics, Vol. 12, No. 4 (Jul.), 1898a, pp. 373-397 e 395.

VEBLEN, Thorstein. The Theory of the Leisure Class: An Economic Study of Institutions. New York: B.W. Huebsch, 1918. 